\title{
FACTORS AFFECTING THE SPEED OF AGGLUTINATION IN THE COOMBS TEST
}

\author{
BY \\ I. D. P. WOOTTON \\ From the Serological Laboratory, Royal Army Medical College, London
}

(RECEIVED FOR PUBLICATION JANUARY 26, 1951)

The Coombs test (Coombs, Mourant, and Race, 1945a, 1945b, 1946) has become popular as a sensitive and reliable method of detecting incomplete antibodies. The essential reagent is the serum of an animal (usually a rabbit) which has been immunized with human globulin.

Potent rabbit sera sometimes show a prozone phenomenon (Wootton, 1950 ; Van Loghem, Kresner, Coombs, and Fulton Roberts, 1950). The experiments described here give details of this phenomenon, and provide information on the conditions necessary for maximum sensitivity in the Coombs test.

\section{Experimental}

The reactions studied have all been of the indirect type, in which human red cells were sensitized by incubation with human sera containing incomplete anti- $D$ antibody. For brevity the human sera will be called "anti- $D$," and the rabbit anti-human globulin sera will be denoted "A.H.G."

Method.-Tubes containing red-cell suspension and anti- $D$ were incubated at $37^{\circ} \mathrm{C}$. for 30 minutes unless otherwise stated. The cells were then washed three times (by centrifuging) with large quantities of saline, followed by the addition of sufficient saline to make a $10 \%$ suspension. A standard volume of each suspension was placed on a white tile and an equal volume of A.H.G. was added and rapidly mixed. The mixed drops were spread over a known area and the tile was rocked and transilluminated.

The time from the start of rocking to the appearance of the first naked-eye agglutination was measured to the nearest second. Observation was continued for five minutes.

Red Cell Suspension.-A standard volume of a $20 \%$ washed suspension in saline was placed in each tube. The suspensions were freshly made each day, using the same donor of genotype $R_{1} r(C D e / c d e)$.

Anti-D. - Several sera were used. They were obtained from women who had become sensitized during pregnancy. Tests for saline agglutinins were negative.

A.H.G.-Two samples were used, prepared by the method described by Wootton (1950). Both reagents were potent, M.C.2 being about four to eight times as strong as M.C.1 The former readily agglutinated sensitized cells when it was diluted 1 in 100,000 .

\section{Results}

Effect of Diluting A.H.G.-A large stock of sensitized and washed cells was prepared and agglutinations were performed with equal volumes of cell suspension and various dilutions in saline of two samples of A.H.G. The dilutions ranged 
FIG. 1.-Effect of diluting A.H.G. Curve A, using A.H.G. 1; curve B, A.H.G. 2; curve C, A.H.G. 2 agglutinating weakly sensitized cells.

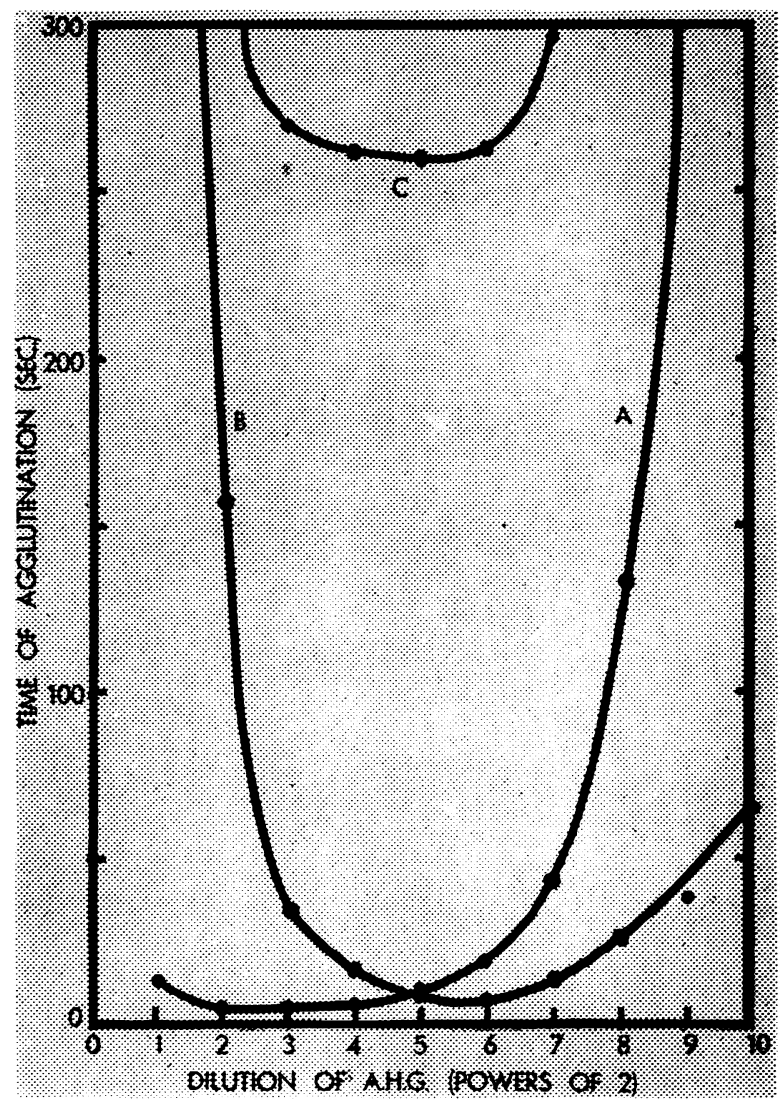

from 1 in 2 to 1 in 1,024 . The anti- $D$ used (MU) caused strong but not complete sensitization of the cells.

The results are shown in Fig. 1. For each sample of A.H.G. there was an optimum concentration at which agglutination occurred most readily. Agglutination was delayed if the reagent was used either at higher or lower dilutions.

To determine whether the same prozone occurred with weakly sensitized cells, the experiment was repeated using cells sensitized with anti-D diluted 1 in 16 . A similar optimum concentration was found, although agglutination was, of course, delayed.

Effect of Diluting anti-D. - Sera containing anti- $D$ were serially diluted with normal serum containing no incomplete antibody. One volume of each dilution was then used to sensitize one volume of red cell suspension. Typical results are shown in Figs. 2 and 3.

In Fig. 2 the A.H.G. was used at a dilution greater than its optimum. Agglutination therefore occurred relatively slowly. With sample MU of anti- $D$, dilution of the antibody increased the time for agglutination in a fairly regular manner. Serum $E C$, on the other hand, contained more anti- $D$, and dilution did not affect agglutina- 


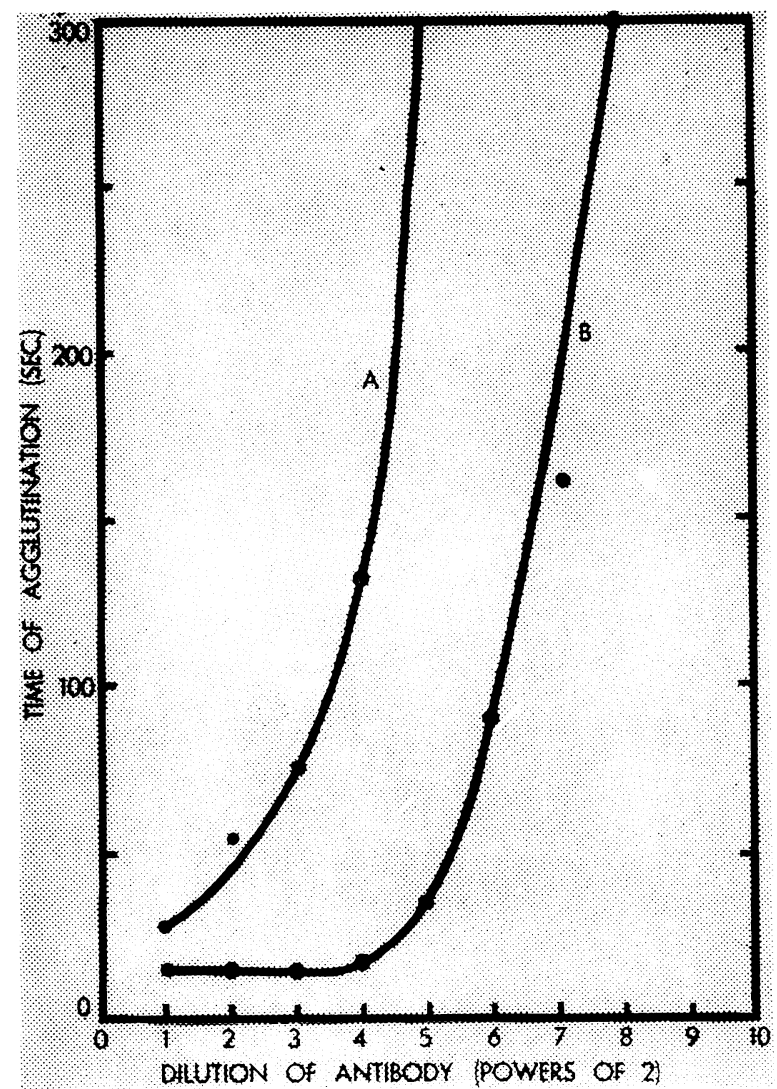

FIG. 2.- Effect of diluting the antibody, when the A.H.G. is used at a dilution greater than its optimum. Curve $\mathrm{A}$, anti-D (MU); curve B, anti-D (EC).

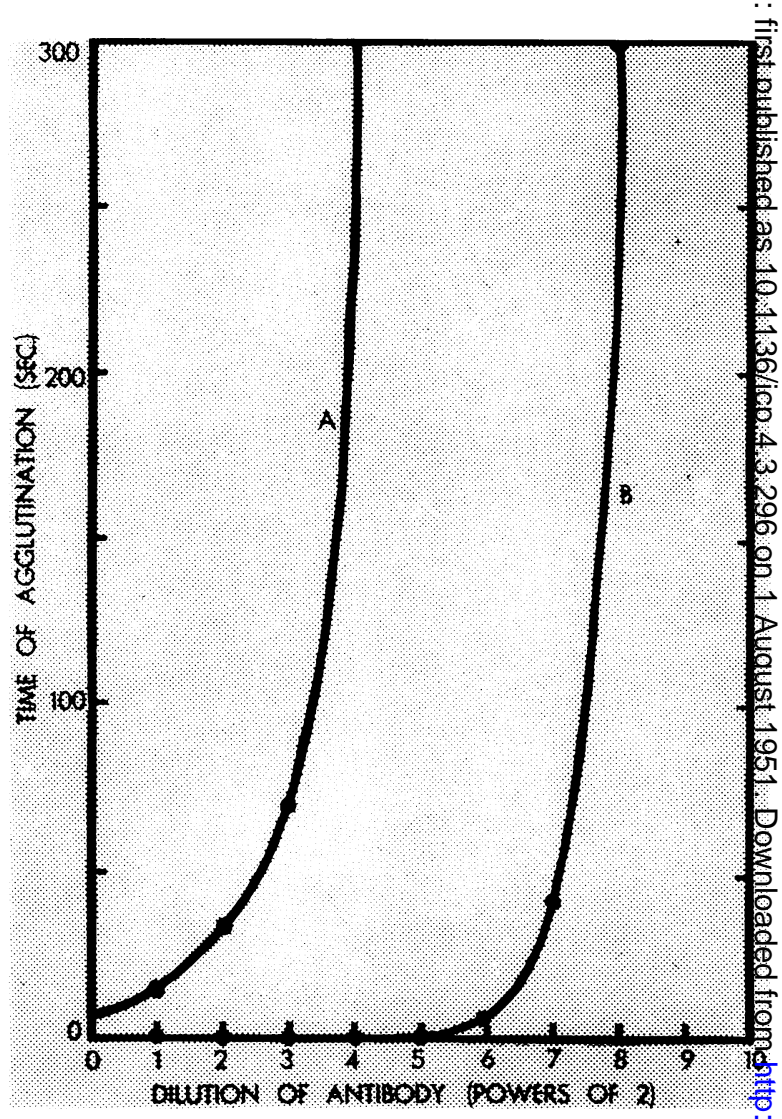

FIG. 3.-Effect of diluting the antibody, when the A.H.G. हु used at its optimum dilution. Curve A, anti-D (MU) curve B, anti-D (EC).

tion when the serum was present at a concentration of 1 in 16 or greater. It is concluded that this minimum time represented the time required to agglutinate fully sensitized cells.

This conclusion was supported by the results shown in Fig. 3, which refers to a similar experiment in which the A.H.G. was used at its optimum titre. With anti- $D$ serum MU there was a similar relation between antibody concentration and agglutination time. As before, anti- $D$ serum EC produced agglutination in the minimum time when present in concentration greater than 1 in 16 or 1 in 32 . Under these conditions, A.H.G. at its optimum titre was agglutinating fully sensitized cells. The agglutination occurred instantaneously as the drop was being mixed, so that the red cell mass broke into coarse fragments as soon as the tile was tilted.

Effect of Adding Normal Serum to anti-D.-A series of numbered tubes was prepared, each tube containing one volume of anti- $D$ serum MU. Inactive normal serum was then added to tubes 2 to 6 in the amounts specified in Fig. 4 . Red cell suspension ( 1 volume) was then added to each tube and the contents were well 


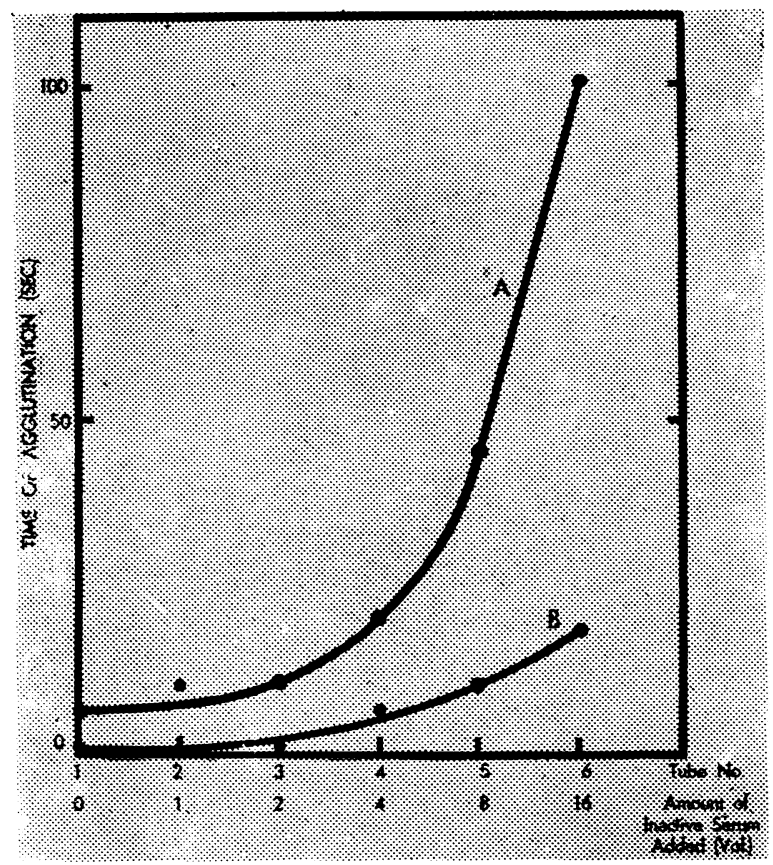

FIG. 4.-Effect of adding inactive serum. Curve A, when incubated $30 \mathrm{~min}$.; curve $\mathrm{B}$, incubated $4 \mathrm{hrs}$.

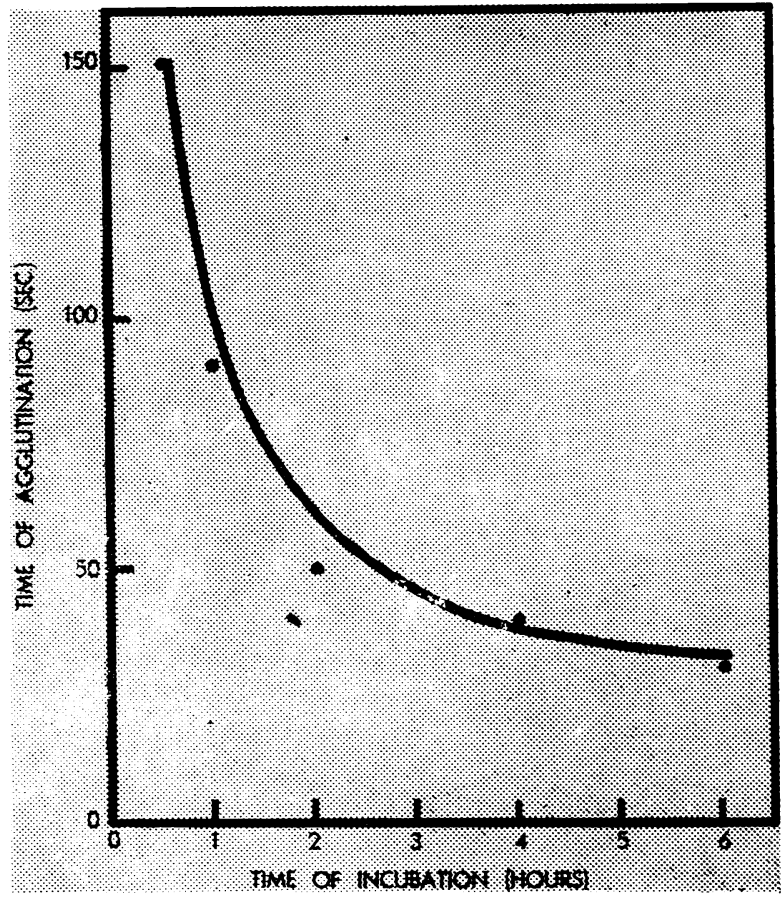

FIG. 5.-Effect of the time of incubation on the, agglutination.

mixed. After incubation for 30 minutes the cells were washed and tested as usual (Fig. 4).

Each tube contained the same quantity of antibody and red cells. In spite of this, agglutination was delayed by the dilution of the anti- $D$ with normal serum. Further experiments showed that sensitized cells did not lose their coating of anti- $D$ when incubated with saline or normal serum. Thus the weak reactions were presumably caused by the cells' failure to combine with the available antibody when it was in dilute solution.

The experiment was then repeated, using an incubation period of four hours, during which the cell suspensions were shaken at 30-minute intervals. As shown in Fig. 4, longer incubation has diminished the dilution effect.

Effect of the Incubation Period.-A quantity of anti- $D$ was suitably diluted with normal serum and mixed with an equal quantity of red cell suspension. The mixture was then incubated for six hours, being shaken each half-hour. At different times portions were removed and the red cells immediately washed. Testing followed in the usual manner.

The curve of Fig. 5 demonstrates that, under these conditions, a 30-minute incubation period is definitely not long enough to produce the strongest reaction. There appears to be little advantage from prolonging incubation beyond six hours.

This experiment was repeated with constant gentle mixing during incubation. No change could be detected in the results. 


\section{Discussion}

The prozone displayed by potent preparations of A.H.G. is a potential danger, in that weak reactions may be missed if the A.H.G. used is too concentrated. Each preparation that has been tested, if potent enough, has shown an optimum dilution, which can readily be determined by a procedure similar to experiment 1 .

The position is more serious if the optimum dilution is different when the A.H.G. is used to detect sensitization of cells by an incomplete antibody other than anti- $D$. This is a point about which information is required. Nevertheless, the above results show that maximum sensitivity cannot be attained with A.H.G. as made in this laboratory unless it is sufficiently potent to show a prozone.

It seems that the following conditions are required for the discovery of the weakest incomplete antibodies: (1) a large volume of serum compared with red cell suspension ; (2) incubation for a prolonged time (e.g., four hours) with frequent shaking; (3) use of a potent A.H.G. at its optimum dilution.

In considering the problem of standardizing A.H.G., two methods present themselves. The dilution at which the A.H.G. becomes inactive may be determined ; if it is a potent reagent, this will be more than 1 in 100,000 . Alternatively, the optimum dilution can be estimated. The former determination requires very large serial dilutions and is affected by the degree of sensitization of the cells, the temperature, time of observation, etc. The latter estimation is easier and does not seem to be affected much, if at all, by the degree of sensitization. Fully sensitized cells should not be used - they agglutinate too quickly-but conditions can be chosen such that the first agglutination occurs after about 10 seconds. Such an estimation will then provide a convenient way of standardization, provided further work shows that the prozone is due to a simple excess of A.H.G. in the sensitized cell v. A.H.G. system.

\section{Summary}

The prozone displayed by potent preparations of anti-human globulin in the Coombs test is described. Conditions necessary for maximum sensitivity in the test are given, and a suggestion is made on the subject of standardizing anti-human globulin sera.

I am indebted to the Director-General, Army Medical Services, for permission to publish this paper. My thanks are due to Dr. R. R. A. Coombs, Miss Marie Cutbush, Dr. G. Fulton Roberts, and Dr. P. L. Mollison for invaluable advice. Mr. F. C. Pinion provided expert technical assistance.

\section{REFERENCE;}

Coombs, R. R. A., Mourant, A. E., and Race, R. R. (1945a). Lancet, $2,15$. (1945b). Brit. J. exp. Path., 26, 255.

Pickles, M. M. (1949). Lancet, 1, 264 . Haemolytic Disease of the Newborn, Oxford.

Van Loghem, J. J., Kresner, M., Coombs, R. R. A., and Roberts, G. Fulton (1950). Lancet, 2, 729.

Wootton, I. D. P. (1950). Nature, Lond., 165, 730. 